\title{
Renal cancer and pneumothorax risk in Birt-Hogg-Dubé syndrome; an analysis of I 5 FLCN mutation carriers from 35 BHD families
}

\begin{abstract}
AC Houweling', LM Gijezen², MA Jonker ${ }^{3}$, MBA van Doorn ${ }^{4}$, RA Oldenburg ${ }^{5}$, KY van Spaendonck-Zwarts ${ }^{6}$, EM Leter', TA van Os', NCT van Grieken ${ }^{8}$, EH Jaspars ${ }^{8}$, MM de Jong ${ }^{6}$, EMHF Bongers ${ }^{9}$, PC Johannesma ${ }^{10}$, PE Postmus $^{10}$, RJA van Moorselaar ${ }^{\prime 1}$, J-HTM van Waesberghe ${ }^{12}$, TM Starink ${ }^{4}$, MAM van Steensel ${ }^{2}$, JJP Gille ${ }^{1}$ and FH Menko*,i

'Department of Clinical Genetics, VU University Medical Center, PO Box 7057, Amsterdam 1007 MB, The Netherlands; ${ }^{2}$ Department of Dermatology, GROW School for Oncology and Developmental Biology, Maastricht University Medical Center, Maastricht, The Netherlands; ${ }^{3}$ Department of Mathematics, VU University, Amsterdam, The Netherlands; ${ }^{4}$ Department of Dermatology, VU University Medical Center, The Netherlands; ${ }^{5}$ Department of Clinical Genetics, Erasmus University Medical Center, Rotterdam, The Netherlands; ${ }^{6}$ Department of Genetics, University Medical Center Groningen, University of Groningen, Groningen, The Netherlands; ${ }^{D}$ Department of Clinical Genetics, Academic Medical Center, Amsterdam, The Netherlands; ${ }^{8}$ Department of Pathology, VU University Medical Center, The Netherlands; ${ }^{9}$ Department of Human Genetics, Radboud University Nijmegen Medical Center, Nijmegen, The Netherlands; ${ }^{10}$ Department of Pulmonology, VU University Medical Center, the Netherlands; "'Department of Urology, VU University Medical Center, The Netherlands; ${ }^{2}$ Department of Radiology, VU University Medical Center, The Netherlands
\end{abstract}

BACKGROUND: Birt-Hogg-Dubé (BHD) syndrome is an autosomal dominant condition caused by germline FLCN mutations, and characterised by fibrofolliculomas, pneumothorax and renal cancer. The renal cancer risk, cancer phenotype and pneumothorax risk of $\mathrm{BHD}$ have not yet been fully clarified. The main focus of this study was to assess the risk of renal cancer, the histological subtypes of renal tumours and the pneumothorax risk in BHD.

METHODS: In this study we present the clinical data of I 5 FLCN mutation carriers from 35 BHD families.

RESULTS: Among 14 FLCN mutation carriers who developed renal cancer 7 were $<50$ years at onset and/or had multifocal/bilateral tumours. Five symptomatic patients developed metastatic disease. Two early-stage cases were diagnosed by surveillance. The majority of tumours showed characteristics of both eosinophilic variants of clear cell and chromophobe carcinoma. The estimated penetrance for renal cancer and pneumothorax was 16\% (95\% minimal confidence interval: 6-26\%) and 29\% (95\% minimal confidence interval: $9-49 \%)$ at 70 years of age, respectively. The most frequent diagnosis in families without identified FLCN mutations was familial multiple discoid fibromas.

CONCLUSION: We confirmed a high yield of FLCN mutations in clinically defined BHD families, we found a substantially increased lifetime risk of renal cancer of $16 \%$ for FLCN mutation carriers. The tumours were metastatic in 5 out of 14 patients and tumour histology was not specific for BHD. We found a pneumothorax risk of $29 \%$. We discuss the implications of our findings for diagnosis and management of $\mathrm{BHD}$.

British Journal of Cancer (201 I) I 05, 1912-1919. doi:10.1038/bjc.2011.463 www.bjcancer.com

(C) 201 I Cancer Research UK

Keywords: Birt-Hogg-Dubé syndrome; folliculin; fibrofolliculoma; renal cancer; discoid fibroma; pneumothorax

Birt-Hogg-Dubé syndrome (BHD, OMIM \#135150) is an autosomal dominant condition characterised by fibrofolliculomas, pneumothorax and renal tumours. BHD is caused by germline mutations in the FLCN gene encoding folliculin (Nickerson et al, 2002). In the original kindred skin lesions were the only clinical manifestation (Birt et al, 1977). Subsequently, renal cancer and pneumothorax were found to be part of the syndrome (Roth et al, 1993; Toro et al, 1999). Furthermore, the risk for colorectal cancer

*Correspondence: Dr FH Menko; E-mail: fh.menko@vumc.nl Received 23 May 2011; revised 15 September 2011; accepted 10 October 201। might be slightly increased in FLCN mutation carriers (Nahorski et al, 2010). The functions of folliculin have partly been clarified and might include a role in the mammalian target of rapamycin pathway (Hasumi et al, 2009). Although many BHD kindreds exhibit all three components of the syndrome, 'pneumothoraxonly' and 'renal-cancer-only' families have also been described (Graham et al, 2005; Painter et al, 2005; Woodward et al, 2008; Kunogi et al, 2010). Among 69 patients with early-onset or familial clear cell renal cancer without further characteristics of BHD, germline FLCN mutations were found in $4 \%$ of cases (Woodward et al, 2008). In recent reviews, the variable clinical manifestations, molecular pathogenesis and management options for BHD were 
Table I Ascertainment of I I F FCN mutation carriers from 35 BHD families considered in this study

\begin{tabular}{|c|c|c|c|c|}
\hline Subdivision of families & Clinical BHD and FLCN mutation & Clinical BHD without FLCN mutation & Other diagnoses & Evaluation declined \\
\hline
\end{tabular}

ancluding 12 families also described by Leter et al, 2008 and Johannesma et al, 2009. ${ }^{b}$ For calculation of renal cancer and pneumothorax penetrance the data of 86 FLCN mutation carriers from 21 kindreds for which complete family data were available were used. 'Seven families (II, 17, 20, 24, 38, 45 and 50) had familial multiple discoid fibromas, described by Starink et al (201 I); two index patients (26 and 39) were diagnosed with pulmonary emphysema and probable tuberous sclerosis complex, respectively.

summarised (Schmidt et al, 2005; Toro et al, 2008; Menko et al, 2009).

For optimal early detection and treatment of BHD-associated renal cancer, insight into the renal cancer risk and the clinical picture of these tumours is essential. Among cohorts of BHD patients a wide range of prevalence of kidney tumours has been observed, ranging from 6.5 to $34 \%$ (Toro et al, 2008). The differences in prevalence are probably due to ascertainment in dermatological

$v s$ urological clinics and age at examination. Notably, the lifetime renal cancer risk for FLCN mutation carriers has not yet been established. In BHD, renal cancer is generally diagnosed at a relatively young age and commonly presents as bilateral and/or multifocal disease. The renal neoplasms typically found in BHD patients were described as hybrid tumours, containing elements of different histological subtypes, in particular chromophobe tumours and oncocytoma. However, other subtypes including clear cell renal carcinoma have also been reported (Pavlovich et al, 2002, 2005; Schmidt et al, 2005; Woodward et al, 2008).

A 50-fold increased risk of spontaneous pneumothorax in BHD was reported (Zbar et al, 2002). Among cohorts of BHD patients the prevalence of pneumothorax ranged from 24 to $38 \%$ (Schmidt et al, 2005; Toro et al, 2007, 2008). Again, ascertainment has varied for cohorts of patients and the lifetime risk of pneumothorax for FLCN mutation carriers has not yet been established. On CT examination of the thorax, more than $80 \%$ of adult BHD patients had multiple lung cysts, most often in the basal lung regions. The presence of lung cysts is probably related to the increased risk for pneumothorax, which is often recurrent in BHD patients (Toro et al, 2007). A positive family history for pneumothorax was associated with an increased risk of pneumothorax and patients with a family history positive for renal cancer had an increased risk of having renal tumours. However, a family history of renal cancer was not associated with an increased pneumothorax risk (Toro et al, 2008).

Previously, we described 25 FLCN germline mutation carriers from 11 BHD families (Leter et al, 2008). Here, we present an update of this cohort and add the evaluation of 24 new kindreds with pathogenic FLCN mutations. In total, the clinical histories of 115 FLCN mutation carriers from 35 BHD families have been assessed. The main focus of this study was to assess the risk of renal cancer, the histological subtypes of renal tumours and the pneumothorax risk in BHD. Furthermore, we consider the yield of FLCN mutation analysis and the clinical phenotype in kindreds without FLCN mutations.

\section{PATIENTS AND METHODS}

\section{Ascertainment of pedigrees}

The BHD database at VU University Medical Center currently lists more than 65 Dutch families referred for suspected BHD; 53 of these kindreds with completed family studies are considered in this report. In all, 40 of these 53 families were referred to our center, whereas other Dutch clinical genetics centers contributed an additional 13 families with pathogenic FLCN mutations (Table 1).

The index patient of 48 out of the 53 families was referred by a dermatologist after fibrofolliculomas were diagnosed. In three BHD families the index patient had renal cancer (BHD families 33, 35 and 63), in one kindred the proband had recurrent pneumothorax (BHD 29). One patient without an identifiable FLCN mutation was referred for multiple pulmonary cysts.

For ascertainment of pedigrees, the proband was requested to inform family members by means of a written summary letter about BHD. After completion of the initial evaluation reminders were sent to probands aimed at complete ascertainment of family members.

\section{Mutation analysis}

After informed consent genomic DNA was extracted from blood samples. Primers for the amplification and sequencing of the 14 exons were detailed previously by Nickerson et al (2002). PCR amplification was performed using a PE 9700 thermocycler (Applied Biosystems, Forster City, CA, USA). Sequencing reactions were performed using Big Dye Terminator (Applied Biosystems) and run on an ABI 3100 genetic analyzer (Applied Biosystems). For the detection of deletions and duplications of one or more exons the SALSA MLPA kit P256 obtained from MRC Holland was used (http://www.mrc-holland.com).

\section{Statistical analysis}

Conditional on the mutation status for different individuals, we assumed the various expressions of the BHD phenotype to be mutually independent and that for individual cases the risks for renal cancer and pneumothorax and the ages at which these traits were expressed are independent. Finally, the penetrances of renal cancer and pneumothorax were assumed to be equal for male and female mutation carriers.

For the estimates of the penetrance of pneumothorax and renal cancer we included 21 out of 22 FLCN-positive pedigrees investigated at our center. For these families medical records of all mutation carriers and information on untested relatives were available. Out of these 21 pedigrees, 20 were ascertained via a proband referred by a dermatologist. One proband (BHD 29) was referred by a pulmonologist for analysis of recurrent pneumothorax. Therefore, we included the proband data in the estimation of renal cancer and pneumothorax risks, with the exception of the proband referred for analysis of pneumothorax.

Major problems of penetrance estimates are missing data and possible preferential testing of individuals affected with complications of BHD, that is, renal cancer or pneumothorax. Indeed, if the mutation status and phenotype had been known for all individuals in all pedigrees the penetrance curves could have been assessed using the Kaplan-Meier estimator. Unfortunately, however, the 

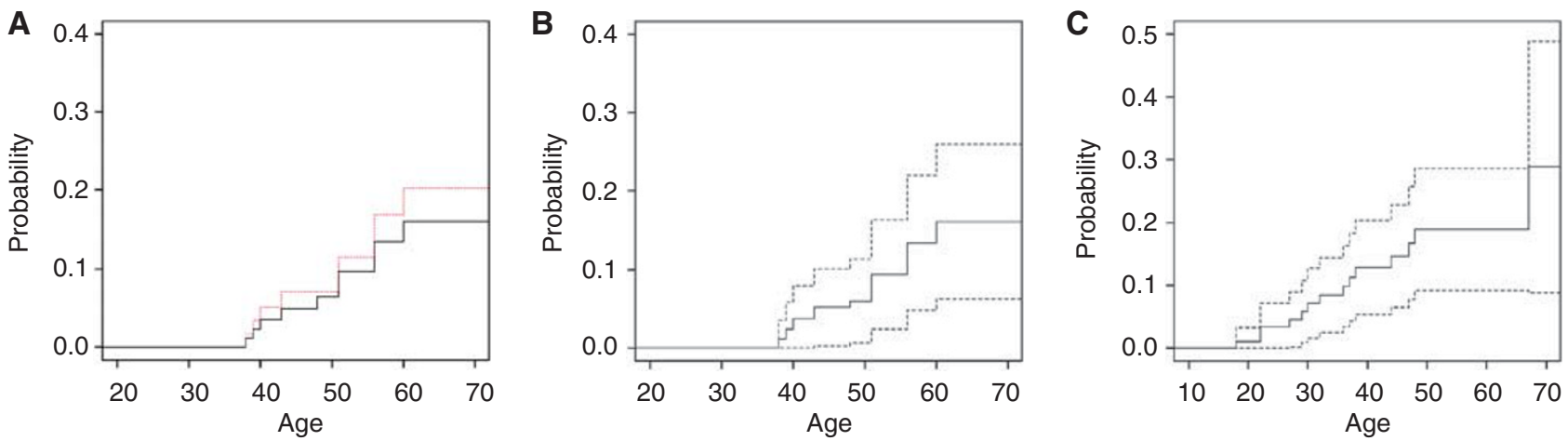

Figure I (A) Estimate of the age-related penetrance function for renal cancer based on available data on both mutation carriers and their untested relatives till the age of 70: $16 \%$ (continuous line $n=86$ mutation carriers and 84 untested relatives), together with the Kaplan-Meier estimator based on the known mutation carriers only at age 70: $20 \%(n=86$, red dashed line). (B) Estimate of the age-related penetrance function for renal cancer based on available data on both mutation carriers and their untested relatives together with a minimum $95 \%$ confidence interval. Estimated penetrance at age 70 : $16 \%$, 95\% minimal confidence interval: (6-26\%). (C) Estimation of the penetrance function of age at the first pneumothorax and a minimum 95\% confidence interval based on available data on both mutation carriers and their untested relatives ( $n=85$ mutation carriers and 84 untested relatives). Estimated penetrance at age 70: 29\%, 95\% minimal confidence interval: (9-49\%).

mutation status or phenotype was not known for all family members. Excluding the individuals for whom the mutation status was unknown would likely lead to an overestimation of risk (see Figure 1A), assuming that non-affected individuals may be less willing to be genotyped. For our corrected risk estimation we assumed that a negative family history for renal cancer or pneumothorax in a close relative indeed reflects the absence of these complications in the untested relative. We imputed the missing data as follows: for every individual in the data set who was not genotyped the probability that he or she was a carrier was computed on the basis of the mutation status of his/her relatives. Subsequently, using this carrier probability it was sampled whether he or she was a mutation carrier or not. As a result, for every individual the mutation status was assigned and in combination with the phenotype Kaplan-Meier curves and confidence intervals were computed. This strategy of sampling the mutation status and estimating the penetrance functions by the Kaplan-Meier estimator was repeated 10000 times. Next, the mean of the 10000 estimated curves and upper and lower bounds of the confidence intervals were computed. These curves are plotted in Figure $1 \mathrm{~A}$ and $\mathrm{B}$ for renal cancer and in Figure $1 \mathrm{C}$ for pneumothorax. By using this strategy the estimator will be asymptotically unbiased. The confidence interval found is slightly too narrow because there is a greater degree of uncertainty than would have been the case if the missing mutation statuses had actually been observed (as assumed after imputation). Therefore, the final confidence interval has a confidence of slightly less than $95 \%$. Although the exact confidences of the intervals are not exactly known we included the calculated intervals in the figures in order to make those who would use the figures for consultation aware of the uncertainty of the given risk estimates.

\section{RESULTS}

The characteristics of 53 families referred for suspected BHD are presented in Table 1. The main features of the BHD kindreds with pathogenic FLCN germline mutations are listed in Table 2. The mutations detected are depicted in Figure 2. Data on the renal tumours and pneumothorax are given in Tables 3 and 4, respectively. Among the 27 families with clinical BHD based on dermatological evaluation at our center, 22 had pathogenic FLCN mutations (mutation detection rate $81 \%$ ). Characteristics of the five families without a detectable FLCN mutation are summarised in Table 5; they include two families with an unclassified exon 1
Table 2 Main features of I I5 FLCN mutation carriers from $35 \mathrm{BHD}$ kindreds with pathogenic FLCN germline mutations

\begin{tabular}{|c|c|c|c|c|}
\hline $\begin{array}{l}\text { Family } \\
\text { no. }\end{array}$ & $\begin{array}{l}\text { FLCN germline } \\
\text { mutation }\end{array}$ & $\begin{array}{l}\text { No. of } \\
\text { FLCN } \\
\text { mutation } \\
\text { carriers }\end{array}$ & $\begin{array}{c}\text { No. of } \\
\text { mutation } \\
\text { carriers with } \\
\text { pneumothorax }\end{array}$ & $\begin{array}{l}\text { No. of } \\
\text { mutation } \\
\text { carriers } \\
\text { with } \\
\text { renal } \\
\text { cancer }\end{array}$ \\
\hline$\left.\mathrm{BHD}\right|^{\mathrm{a}}$ & c.610_6II delinsTA & 6 & 2 & I \\
\hline $\mathrm{BHD} 3^{\mathrm{a}}$ & c.420delC & 2 & 0 & 0 \\
\hline $\mathrm{BHD} 4^{\mathrm{a}}$ & c. I285dupC & I & 0 & 0 \\
\hline $\mathrm{BHD} 6^{\mathrm{a}}$ & c. 1285 dupC & 4 & 0 & 2 \\
\hline $\mathrm{BHD} 8^{\mathrm{a}}$ & c.655dupG & 2 & 0 & 0 \\
\hline $\mathrm{BHD} 12^{\mathrm{a}}$ & c.1285dupC & 3 & 0 & 0 \\
\hline $\mathrm{BHD} 14^{\mathrm{a}}$ & c.610_6IIdelinsTA & 3 & I & 0 \\
\hline $\mathrm{BHD} 15^{\mathrm{a}}$ & $c .619-1 G>A$ & 4 & I & 0 \\
\hline $\mathrm{BHD} 16^{\mathrm{a}}$ & c.610_6IIdelinsTA & 18 & 2 & । \\
\hline $\mathrm{BHD} 18^{\mathrm{a}}$ & $\begin{array}{l}\text { c. [130-1-7_I304del I I; } \\
\text { I323delCinsGA] }\end{array}$ & 2 & I & 0 \\
\hline $\mathrm{BHD} 19^{\mathrm{a}}$ & c.619-1G>A & I & 0 & 0 \\
\hline BHD 22 & c.1285dupC & I & 0 & 0 \\
\hline BHD 23 & c.319_320delGTinsCAC & | | & I & 1 \\
\hline BHD 27 & $\begin{array}{l}\text { c. } 140 \overline{8} \_|4| 8 \text { delGGGAG } \\
\text { CCCTGT }\end{array}$ & I & 0 & 0 \\
\hline $\mathrm{BHD} 29^{\mathrm{b}}$ & c.610_6II delinsTA & 2 & 2 & 0 \\
\hline BHD 30 & c. $128 \overline{5}$ dupC & I & 0 & 0 \\
\hline $\mathrm{BHD} 31$ & c.610_6IIdelinsTA & I & 0 & 0 \\
\hline BHD 32 & c.469_47I delTTC & 3 & 3 & । \\
\hline BHD 33 & $c .619-1 G>A$ & 2 & I & I \\
\hline BHD 35 & c.1749_1753del & 2 & I & I \\
\hline BHD 36 & c.610_- 61 IdelinsTA & I & 0 & 0 \\
\hline BHD 37 & c.319_320delGTinsCAC & 15 & 2 & I \\
\hline BHD 40 & c. $118 \overline{3} \_1198 \mathrm{del}$ & I & 0 & 0 \\
\hline BHD 43 & c.610_6II delinsTA & 5 & 5 & 2 \\
\hline BHD 44 & c.319_320delGTinsCAC & 2 & 0 & । \\
\hline $\mathrm{BHD} 46$ & $\begin{array}{l}\text { c. }\left|40 \overline{8} \_\right| 4 \mid 8 \text { delGGGAG } \\
\text { СCСTGT }\end{array}$ & 6 & 0 & 1 \\
\hline BHD 47 & c. $1177-2 A>G$ & 2 & 0 & 0 \\
\hline BHD 48 & c.1285dupC & 1 & 0 & 0 \\
\hline BHD 49 & c. $1300 G>C$ & I & 0 & 0 \\
\hline BHD 5I & c.1285dupC & I & 0 & 0 \\
\hline BHD 53 & $\begin{array}{l}\text { c.87I+3_87I+4delGAins } \\
\text { TCCAGAT }\end{array}$ & I & 0 & 0 \\
\hline BHD 57 & $\begin{array}{l}\text { c.250-?_| } 740+\text { ?del } \\
\text { (del exon } 5-14)\end{array}$ & 3 & 2 & 0 \\
\hline BHD 62 & $\begin{array}{l}\text { c. }|30|-?-\mid 740+\text { ?del } \\
\text { (del exon } 12-14 \text { ) }\end{array}$ & 3 & 3 & 0 \\
\hline BHD 63 & c.610_61 IdelinsTA & 2 & । & I \\
\hline BHD 66 & c. $3 G>A$ & I & 0 & 0 \\
\hline
\end{tabular}

aDescribed by Leter et al, 2008. ' Described by Johannesma et al, 2009. 


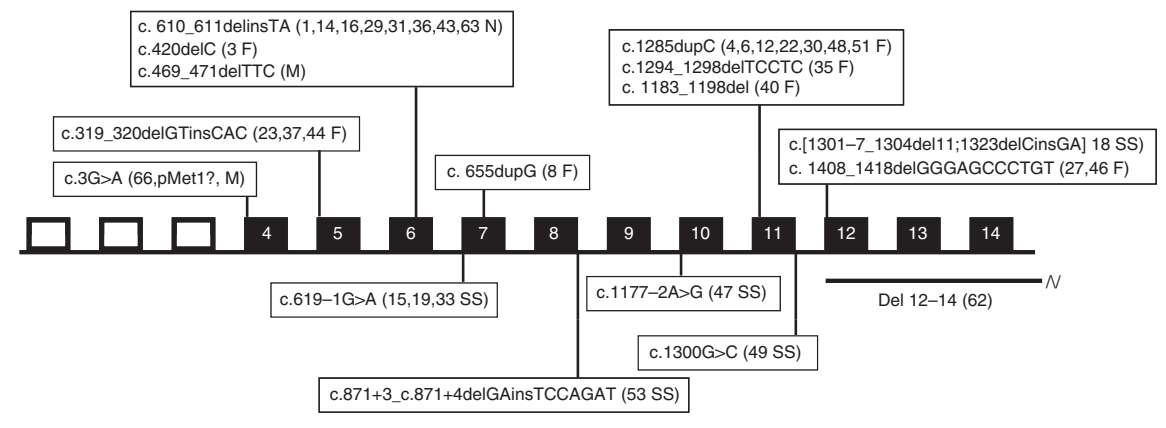

Del 5-14 (57)

Figure 2 Overview of the FLCN mutations identified in this study. Del: deletion, F: frameshift, M: missense, N: nonsense, SS: splice site. Exons are depicted as rectangles. The family numbers are shown after the mutations.

Table 3 Main features of 17 renal cancers in 14 FLCN germline mutation carriers from 12 BHD kindreds

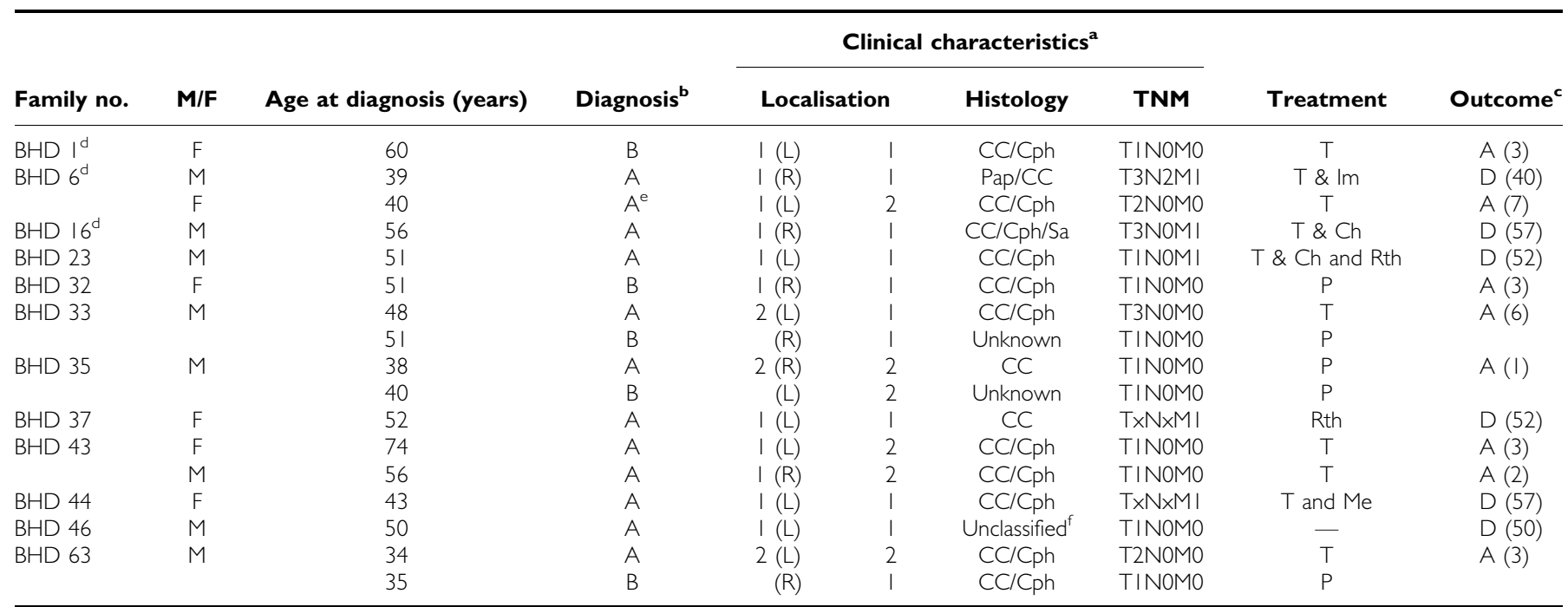

Abbreviations: $\mathrm{Ad}=$ adenocarcinoma, classification not certain; $\mathrm{BHD}=$ Birt-Hogg-Dubé; $\mathrm{CC}=$ clear cell; $\mathrm{CC} / \mathrm{Cph}=$ renal cell carcinoma with eosinophilic cytoplasm and characteristics of both $\mathrm{CC}$ and $\mathrm{Cph} ; \mathrm{Ch}=$ chemotherapy; $\mathrm{Cph}=$ chromophobe; $\mathrm{F}=$ female; $\mathrm{Im}=$ immunotherapy; $\mathrm{P}=$ partial nephrectomy; $\mathrm{M}=$ male; $P$ ap $=$ papillary; Rth = radiotherapy; $\mathrm{Me}=$ metastasectomy; $\mathrm{Sa}=$ sarcomatoid component; $\mathrm{T}=$ total nephrectomy; $\mathrm{TNM}=$ classification according to tumour/node/metastasis status. aLocalisation: left column: I/2: unilateral/bilateral, in parentheses: LR: left-sided/right-sided, right column: I: unifocal, 2: multifocal. Histology: according to Lopez-Beltran et al, 2009. ' ${ }^{\mathrm{A}}$ : diagnosis after symptoms had developed; B: diagnosis after positive renal imaging of an asymptomatic individual. ${ }^{\mathrm{C}} \mathrm{A}$ : alive, $\mathrm{D}$ : deceased; in parentheses: number of years of follow-up and age at death, respectively. ${ }^{\mathrm{d} D e s c r i b e d}$ by Leter et al, 2008. ${ }^{\mathrm{e}} \mathrm{Coincidental}$ finding at medical examination for gastrointestinal complaints. ${ }^{\mathrm{f} T h e}$ tumour was found during autopsy and could not be reliably subclassified due to autolysis.

deletion. Analysis of these exon 1 deletions is ongoing. In the cohort of our current study, no colorectal cancer was reported. Colorectal adenomas were diagnosed by colonoscopy in four FLCN mutation carriers (age 40,42, 83, these patients were also included in our previous reports by Leter et al, 2008 and Nahorski et al, 2010 and age 44, not reported previously).

Other malignancies than renal cancer were reported in six patients previously documented in Leter et al (2008). In addition to the patients reported by Leter et al (2008) in five patients without renal cancer, tumours were reported including non-melanoma skin cancer in two patients and single cases of melanoma, sarcoma, bladder and prostate cancer. The patient diagnosed with melanoma was also diagnosed with sarcoma. Three patients with renal cancer were diagnosed with additional tumours. One patient had oncocytic pituitary adenoma at age 9 , astrocytoma at age 12 , pheochromocytoma at age 34 and renal cancer at age 34 and 35 (BHD 63, Table 3). No evidence for other tumour susceptibility was found. The other two patients had gastric carcinoma at age 55 and renal cancer at age 56 (BHD 43, M, Table 3) and prostate carcinoma and renal cancer at age 50 (BHD 46, Table 3), respectively.

\section{Renal manifestations}

In all, 14 out of 115 (12\%) FLCN mutation carriers from 12 families were diagnosed with renal cancer. All available tumours were revised at our center by two pathologists. In addition, one mutation carrier had renal oncocytoma (BHD 57). Five mutation carriers died of metastatic renal cancer (BHD 6, BHD 16, BHD 23, BHD 37 and BHD 44; Table 3). All were diagnosed with renal cancer after symptoms had developed. The histological classification of the renal tumours according to the WHO criteria is shown in Table 3 (Lopez-Beltran et al, 2009). Most of the tumours showed cells with granular/floccular eosinophilic cytoplasm, as can be seen in both clear cell carcinoma (formerly called the eosinophilic variant, Table 3) and chromophobe carcinoma. This eosinophilic cell variation is also often seen in sporadic clear cell carcinoma (Kummerlin et al, 2009; Lopez-Beltran et al, 2009). As most tumours had mainly eosinophilic cytoplasm, with moderately sharp cell borders, a vague perinuclear halo and moderately enlarged nuclei, we classified them as intermediate between clear cell and chromophobe carcinoma (CC/Cph) (Table 3 and Figure 3). 
One of the tumours showed sarcomatoid changes, which can develop in both clear cell and chromophobe carcinoma (Table 3, BHD 16). One other tumour had papillary structures in combination with clear cell changes (Table 3, BHD 6). Two additional patients from $F L C N$ positive families but with unknown mutation carrier status (BHD 1 and BHD 42) were diagnosed with renal cancer. These two tumours also showed mixed chromophobe/clear cell histology. In all, 2 of the 14 renal tumours (BHD 1 and BHD 32, Table 3) were detected by surveillance. For one of these patients

Table 4 Main features of pneumothorax in 28 FLCN germline mutation carriers from 15 BHD kindreds

\begin{tabular}{|c|c|c|c|c|c|}
\hline \multirow[b]{2}{*}{ Family no. } & \multirow[b]{2}{*}{ M/F } & \multirow{2}{*}{$\begin{array}{c}\text { Age at } \\
\text { diagnosis }\end{array}$} & \multicolumn{3}{|c|}{ Clinical characteristics } \\
\hline & & & $R / L$ & Episodes & Renal cancer \\
\hline \multirow[t]{2}{*}{$\left.\mathrm{BHD}\right|^{\mathrm{a}}$} & $\mathrm{F}$ & 44 & $\mathrm{~L}$ & 1 & \\
\hline & $M$ & 30 & $\mathrm{R}$ & 1 & \\
\hline $\mathrm{BHD} \mid 4^{\mathrm{a}}$ & $M$ & 36 & $L$ & 1 & \\
\hline $\mathrm{BHD} 15^{\mathrm{a}}$ & $\mathrm{F}$ & $\cup$ & $\cup$ & 1 & \\
\hline \multirow[t]{2}{*}{$\mathrm{BHD} 16^{\mathrm{a}}$} & $M$ & 67 & $L$ & 1 & \\
\hline & $\mathrm{F}$ & 47 & U & 1 & \\
\hline $\mathrm{BHD} \mid 8^{\mathrm{a}}$ & $M$ & 22 & $\cup$ & | & \\
\hline $\mathrm{BHD} 23$ & $M$ & 22 & $\mathrm{~L}$ & i & \\
\hline \multirow{2}{*}{$\mathrm{BHD} 29^{\mathrm{b}}$} & $M$ & 25 & B & 5 & \\
\hline & $M$ & 27 & B & 1 & \\
\hline \multirow[t]{3}{*}{$\mathrm{BHD} 32$} & $\mathrm{~F}$ & 39 & $\cup$ & I & 51 \\
\hline & $\mathrm{F}$ & $\cup$ & $\cup$ & 1 & \\
\hline & $M$ & 23 & $\cup$ & 1 & \\
\hline BHD 33 & $M$ & $\cup$ & $\cup$ & 1 & \\
\hline $\mathrm{BHD} 35$ & $M$ & 38 & $\mathrm{R}$ & 2 & 38 \\
\hline \multirow[t]{2}{*}{$\mathrm{BHD} 37$} & $\mathrm{~F}$ & 48 & B & I & 51 \\
\hline & $\mathrm{F}$ & 29 & $\mathrm{R}$ & i & \\
\hline BHD 63 & $M$ & 37 & $B$ & i & \\
\hline \multirow[t]{3}{*}{$\mathrm{BHD} 62$} & $M$ & 53 & $\mathrm{~L}$ & 7 & \\
\hline & $M$ & 27 & $\mathrm{~L}$ & 1 & \\
\hline & $M$ & 42 & B & 3 & \\
\hline \multirow[t]{5}{*}{ BHD 43} & $\mathrm{~F}$ & 38 & $L$ & 1 & \\
\hline & $M$ & 37 & $\mathrm{R}$ & 4 & \\
\hline & $\mathrm{F}$ & 74 & L & 1 & 74 \\
\hline & $M$ & 32 & $L$ & 3 & 55 \\
\hline & $\mathrm{F}$ & 18 & $\mathrm{R}$ & 2 & \\
\hline \multirow[t]{2}{*}{ BHD 57} & $M$ & 31 & $\mathrm{~L}$ & 1 & \\
\hline & $\mathrm{F}$ & 33 & $\mathrm{R}$ & 5 & \\
\hline
\end{tabular}

Abbreviations: $L=$ left lung; $R=$ right lung; $M=$ male; $F=$ female; $B=$ bilatera $U=$ available records did not state exact age/clinical characteristics. Age at diagnosis: Age at diagnosis of the first episode of pneumothorax. Renal cancer: Age at diagnosis of renal cancer in patients with a history of pneumothorax. 'Described by Leter et al 2008. 'Described by Johannesma et al, 2009. The relative diagnosed with a clear cell renal tumour was not tested for the FLCN mutation.

Table 5 Characteristics of BHD probands without an identified FLCN mutation renal cancer was detected on the first ultrasound performed after the diagnosis BHD was made (BHD 32, Table 3). For the other patient renal cancer was detected by ultrasound 4 years after the preceding normal ultrasound/MRI (BHD 1, Table 3); the latter patient did not undergo standard yearly surveillance after the initial imaging.

\section{Cutaneous manifestations}

Most FLCN mutation carriers $(91 / 115,79 \%)$, underwent dermatological evaluation ( 68 of which were evaluated by dermatologists at our center). In all 19 (21\%) cases, aged 23-72 years, had no cutaneous abnormalities; $14(74 \%)$ of the patients without cutaneous manifestations were over age 40 . Notably, one patient who presented with metastatic renal cancer at age 51 (BHD 23) had no cutaneous lesions. The youngest mutation carrier with histologically confirmed fibrofolliculomas was 25 years old (BHD 23). In five families without an identifiable FLCN mutation (BHD 2, $5,9,25$ and 28) the clinical diagnosis BHD was based on histologically confirmed multiple fibrofolliculomas; in one of these kindreds both pneumothorax and renal cancer occurred (BHD 25, Table 5). In seven families without FLCN mutations the skin lesions consisted of multiple discoid fibromas of childhood onset (families 11, 17, 20, 24, 38, 45 and 50). In two of these families (24 and 45) a genealogical study showed common ancestry. No renal or pulmonary signs were present in these seven families, except for one case with pneumothorax. For two of these families the FLCN-locus was excluded by linkage analysis (Starink et al, 2011).

\section{Pulmonary manifestations}

Among the 115 FLCN mutation carriers, 28 (24\%) had a history of pneumothorax, recurrent in eight patients (Table 4). In all, 4 out of 28 patients with a previous pneumothorax were confirmed (former) smokers. The medical records of the other patients did not state a history of smoking. The mean age of the first pneumothorax was 36 years (range 18-74 years). We did not systematically subject mutation carriers to CT scanning of the lungs. For 12 FLCN mutation carriers the report of a CT-scan of the thorax was available. Scans were performed either to confirm suspected BHD or because of pulmonary complications of BHD. In five of these patients (aged 25-46 years), multiple cysts were reported in one or both lungs. Of these, two had a history of recurrent or bilateral pneumothorax before the age of 30 years. In seven FLCN mutation carriers no pulmonary cysts were detected (age 23-71, four were over age 40).

\section{Cumulative renal cancer and pneumothorax risk}

The estimated renal cancer penetrance based on assessment of FLCN mutation carriers only was $20 \%$ at age 70 (red dashed line,

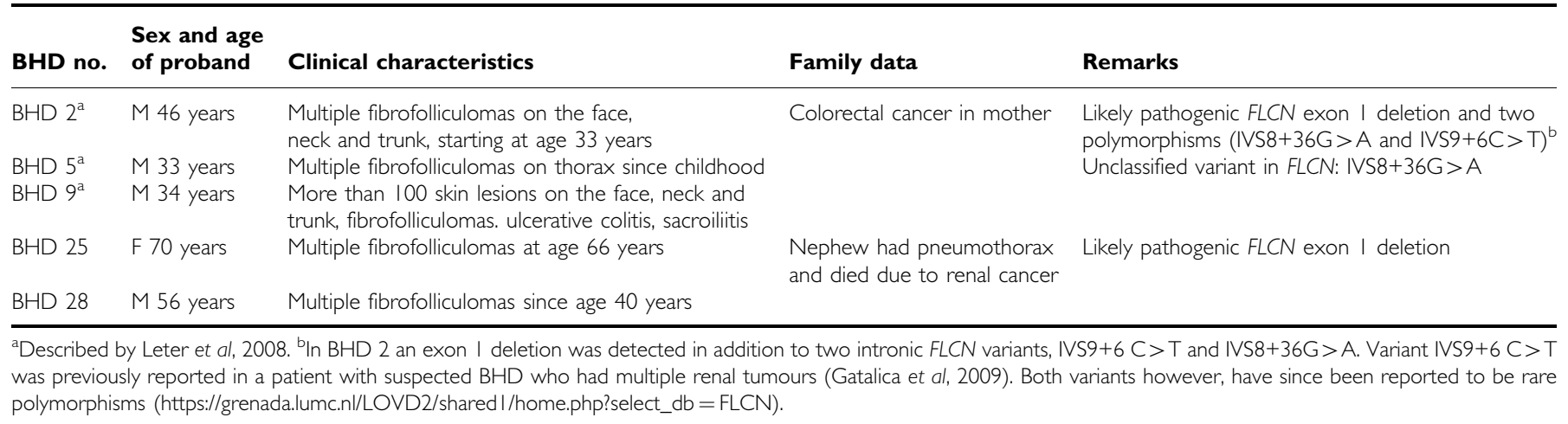



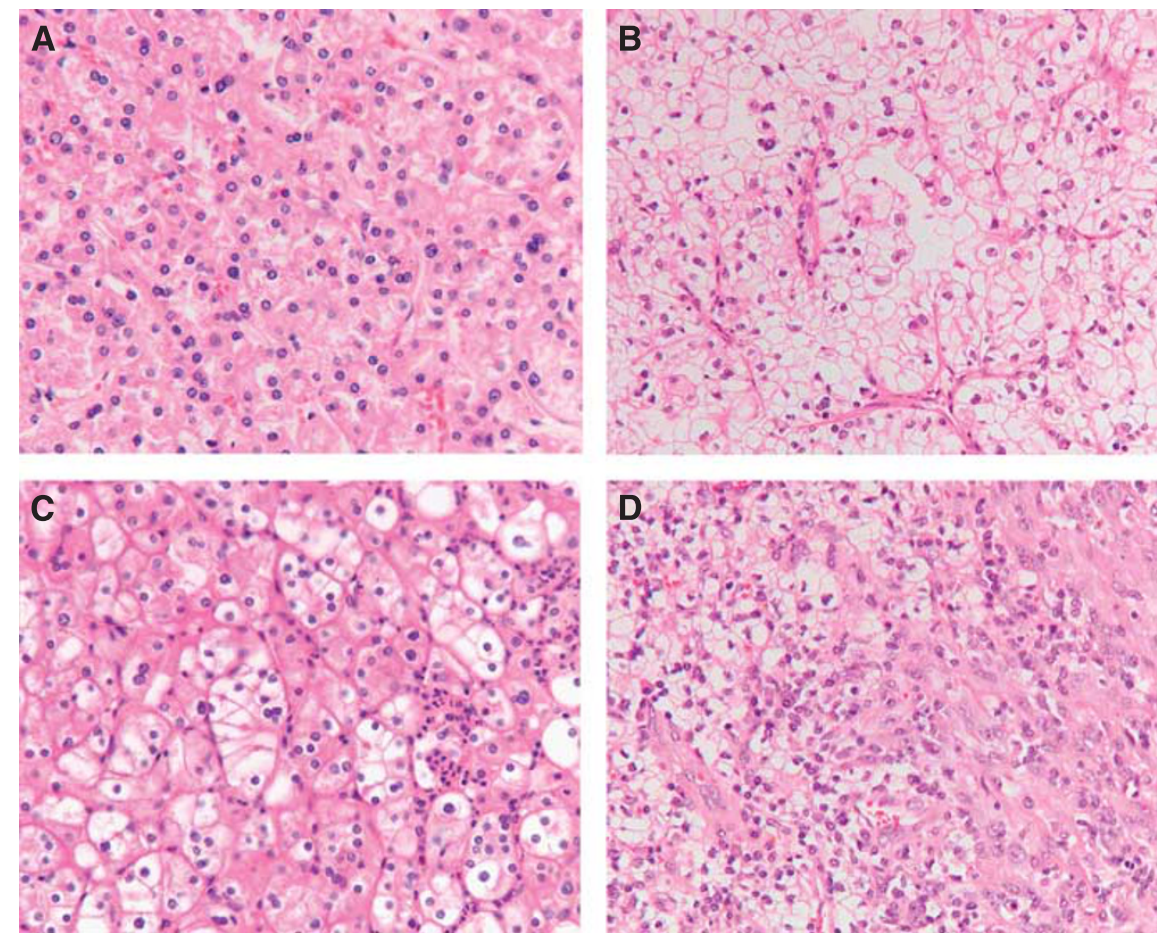

Figure 3 Illustration of the histological pictures of renal cell carcinomas in our series. (A) The most common pattern found, classified as clear cell/ chromophobe. The tumour cells show eosinophilic cytoplasm, moderate nuclear pleiomorphism, vague perinuclear halos, no explicit cell borders and no vascular prominence. (B) Classical picture of clear cell carcinoma, as can be seen in many of the tumours in our series, but mostly only in part of the tumour cells. (C) A clear cell/chromophobe renal cell carcinoma with partially clear cytoplasm, more prominent cell borders, no thick-walled vessels. (D) Renal cell carcinoma with sarcomatoid changes (in the right part of the picture).

Figure 1A). In contrast, when considering both tested and untested relatives, the estimated renal cancer penetrance at age 70 was $16 \%$ (continuous line, Figure 1A and B). The estimated penetrance for the first episode of spontaneous pneumothorax was $29 \%(95 \%$ minimal confidence interval: $9-49 \%$, Figure $1 \mathrm{C}$ ) at 70 years, again considering information on both mutation carriers and their untested relatives.

\section{DISCUSSION}

An important aim of this study was the estimation of renal cancer and pneumothorax penetrance in BHD. By incorporating data on relatives who did not undergo DNA testing we found an estimated penetrance for renal cancer of $16 \%$ and a penetrance for pneumothorax of $29 \%$ at the age of 70 years. The wide range of prevalence for renal cancer among cohorts of BHD reported in literature is $6.5-34 \%$ (Toro et al, 2007, 2008; Kunogi et al, 2010). The renal cancer risk we found of around $16 \%$ at age 70 years is important for counselling of FLCN mutation carriers and their families ascertained in cancer family clinics. Future studies with larger patient groups and comparison between cohorts investigated in different populations may lead to further specification of the renal cancer risk.

The clinical presentation, histological pattern and biological behaviour of renal cancer in FLCN mutation carriers are important for several reasons. First, a pathognomonic histological pattern would be helpful for early diagnosis. Previously, The European BHD Consortium proposed clinical diagnostic criteria for BHD, which included early-onset, bilateral and multifocal renal tumours and a mixed chromophobe and oncocytic histological pattern. In addition, FLCN mutation analysis should be considered for patients who have familial cystic lung disease, familial pneumothorax, familial renal cancer, or any combination of spontaneous pneumothorax and kidney cancer (Menko et al, 2009).

Notably, among 14 BHD patients in the current study who developed renal cancer, clinical signs of hereditary disease (age at onset $<50$ years and/or multifocal/bilateral tumours) were present in only seven cases. In addition, the histological picture of BHDassociated renal cancer in this cohort was not typical for this syndrome. In all, 10 out of 14 renal tumours revised in this series were difficult to classify. None of them showed classical features of chromophobe renal cell carcinoma. Instead, they mainly exhibited characteristics of both eosinophilic variants of clear cell cancer and chromophobe carcinoma. One of the tumours was a hybrid form of clear cell and papillary carcinoma and one showed sarcomatoid changes. These histological patterns can also be found in sporadic RCC. Therefore, late-onset unilateral, unifocal clear cell renal cancer does not exclude BHD.

Furthermore, although BHD-associated renal tumours were reported to metastasise rarely (Toro et al, 2008), 5 of the 14 patients with renal cancer in our cohort developed metastatic disease underlining the importance of early detection of these renal tumours by surveillance. In recently diagnosed families not included in this report, we observed two BHD patients with renal cancer at the ages of 30 and in the early twenties, respectively, underlining that surveillance for renal cancer should be offered to BHD patients from early age onward.

Of the 115 FLCN mutation carriers 28 had a history of pneumothorax, frequently recurrent and bilateral. The mean ages at which pneumothorax and renal cancer occurred in our cohort were 36 and 49 years, respectively. Among the 14 renal cancer patients described five had a history of pneumothorax (Tables 3 and 4), preceding renal cancer by several years in three patients (BHD 32, 37, 43, Table 4). Although an increased risk for renal cancer in BHD families with a positive history for pneumothorax 
has not been observed (Toro et al, 2008), bilateral, recurrent or familial pneumothorax may serve as an early indicator of BHD syndrome (Johannesma et al, 2009).

Ever since Hornstein and Knickenberg (1975) described the combination of skin fibrofolliculomas and colorectal polyps it is a matter of debate whether BHD is associated with an increased risk of colorectal neoplasia. Although Zbar et al (2002) found no significantly increased risk Khoo et al (2002) proposed that the risk might apply to specific subgroups only. Nahorski et al (2010) found evidence that the risk may be dependent on the FLCN genotype. Recently, in family BHD15, one of the FLCN mutation carriers developed symptomatic colonic cancer at age 62 years. Late-onset colorectal cancer has been diagnosed in several other FLCN mutation carriers from our BHD cohort not included in the present study. Although colorectal cancer may well be coincidental in these cases the current data call for further evaluation of the colorectal neoplasia risk in BHD.

Among 27 families with clinical BHD (multiple fibrofolliculomas) evaluated at our center 22 had pathogenic FLCN mutations, resulting in a $81 \%$ yield for FLCN mutation analysis. Four patients referred for suspected BHD declined genetic testing.

In two of the families (BHD 2 and 25) with clinical BHD but without a mutation in the coding region of FLCN, a deletion of exon 1 was observed. Exon 1 is the first of three non-coding exons. The exact size and the effect of these deletions remain to be determined. Recently, after completion of our study, intragenic deletions and a duplication were reported in patients with BHD (Benhammou et al, 2011). Using a luciferase reporter assay, this study also showed that the expression was strongly reduced when exon 1 was deleted. Analysis of the pathogenicity and cosegregation of the deletions detected in our families are currently ongoing to prove pathogenicity. Therefore, these families were not included in the calculation of the penetrance for renal cancer and pneumothorax, although the deletions are very likely to be pathogenic. In the current study, intragenic deletions were detected in two additional BHD families (BHD 57, 62), underlining the importance of MLPA or CGH analysis in patients with a clinical suspicion of BHD without an identifiable FLCN mutation.

Nine patients referred for possible BHD were diagnosed with other conditions. One patient had probable tuberous sclerosis and one patient had pulmonary emphysema. Seven of the families were diagnosed with familial multiple discoid fibromas (FMDF). In 1985 , one of the authors described this entity as a dominant condition distinct from BHD, showing childhood onset, preferential localisation of lesions on the ears and distinct histology, which mimics the trichodiscomas in BHD (Starink et al, 1985).

\section{REFERENCES}

Benhammou JN, Vocke CD, Santani A, Schmidt LS, Baba M, Seyama K, Wu X, Korolevich S, Nathanson KL, Stolle CA, Linehan WM (2011) Identification of intragenic deletions and duplication in the FLCN gene in Birt-Hogg-Dubé syndrome. Genes Chromosomes Cancer 50(6): $466-477$

Birt AR, Hogg GR, Dubé WJ (1977) Hereditary multiple fibrofolliculomas with trichodiscomas and acrochordons. Arch Dermatol 113(12): 1674-1677

Gatalica Z, Lilleberg SL, Vranic S, Eyzaguirre E, Orihuela E, Velagaleti G (2009) Novel intronic germline FLCN gene mutation in a patient with multiple ipsilateral renal neoplasms. Hum Pathol 40(12): 1813-1819

Graham RB, Nolasco M, Peterlin B, Garcia CK (2005) Nonsense mutations in folliculin presenting as isolated familial spontaneous pneumothorax in adults. Am J Respir Crit Care Med 172(1): 39-44

Hasumi Y, Baba M, Ajima R, Hasumi H, Valera VA, Klein ME, Haines DC, Merino MJ, Hong SB, Yamaguchi TP, Schmidt LS, Linehan WM (2009) Homozygous loss of BHD causes early embryonic lethality and kidney tumor development with activation of mTORC1 and mTORC2. Proc Natl Acad Sci 106(44): $18722-18727$
Thus far no systemic complications have been noted for FMDF except for one patient with pneumothorax. We have now excluded involvement of the FLCN locus in two FMDF kindreds using linkage analysis (Starink et al, 2011).

Currently, we use the renal cancer risk of around $16 \%$ by age 70 years for the counselling of patients to emphasise the importance of surveillance for renal cancer. As according to our histological data, the renal cancers found in BHD were not evidently different from sporadic tumours, future studies aimed at the classification of $\mathrm{BHD}$-associated renal cancer in comparison with sporadic disease are essential. Both the renal cancer risk and the pneumothorax risk (about $16 \%$ and $29 \%$ at age 70 years, respectively) are based on a large set of data using a model incorporating available data of family members not subjected to DNA testing. Evaluation of larger patient groups and patients from other populations may yield other penetrance figures in the future.

The European BHD Consortium (Menko et al, 2009) proposed FLCN mutation testing in patients with early-onset renal cancer ( $<50$ years), in particular with multifocal or bilateral disease (or both) with chromophobe or oncocytic histology and in familial renal cancer cases. Age at diagnosis of (the first) renal cancer in our patient group was at or above 50 years of age in half of the patients and the tumour histology was mixed in most patients but included clear cell elements in all cases. Therefore, it will be important to study the yield of FLCN mutation testing using a wider set of criteria than proposed previously. The histology and molecular pathology of renal tumours are associated with their biological behaviour and reaction to systemic treatment of metastatic disease. Therefore, additional studies are needed to monitor the success of surveillance for renal cancer, the results of surgical or other forms of local treatment such as radiofrequency ablation and response to targeted therapies.

\section{ACKNOWLEDGEMENTS}

We are grateful for the comments and suggestions given by Professor Eamonn Maher, Department of Medical and Molecular Genetics, University of Birmingham, United Kingdom and Professor Hanne Meijers, Department of Clinical Genetics, VU University Medical Center, the Netherlands. We thank Marieke T Kramer and Martijn $\mathrm{H}$ Ploeger for their contributions in collecting patient data. LM Geijzen was supported by the Myrovlytis Trust MAM van Steensel was supported by a Grant from the Dutch Cancer Society KWF (UM2009-4352).
Hornstein OP, Knickenberg M (1975) Perifollicular fibromatosis cutis with polyps of the colon - a cutaneo-intestinal syndrome sui generis. Arch Dermatol Res 253(2): $161-175$

Johannesma PC, Lammers JW, van Moorselaar RJ, Starink TM, Postmus PE Menko FH (2009) Spontaneous pneumothorax as the first manifestation of a hereditary condition with an increased renal cancer risk. Ned Tijdschr Geneeskd 153: A581 (in Dutch)

Khoo SK, Giraud S, Kahnoski K, Chen J, Motorna O, Nickolov R, Binet O, Lambert D, Friedel J, Lévy R, Ferlicot S, Wolkenstein P, Hammel P, Bergerheim U, Hedblad MA, Bradley M, Teh BT, Nordenskjöld M, Richard S (2002) Clinical and genetic studies of Birt-Hogg-Dubé syndrome. J Med Genet 39(12): 906-912

Kummerlin I, ten Kate F, Smedts F, Horn T, Algaba F, Trias I, de la Rosette J, Laguna MP (2009) Diagnostic problems in the subtyping of renal tumors encountered by five pathologists. Pathol Res Pract 205(1): 27 - 34

Kunogi M, Kurihara M, Ikegami TS, Kobayashi T, Shindo N, Kumasaka T, Gunji Y, Kikkawa M, Iwakami S, Hino O, Takahashi K, Seyama K (2010) Clinical and genetic spectrum of Birt-Hogg-Dubé syndrome patients in 
whom pneumothorax and/or multiple lung cysts are the presenting feature. J Med Genet 47(4): 281-287

Leter EM, Koopmans AK, Gille JJP, Van Os TAM, Vittoz GG, David EFL, Jaspars EH, Postmus PE, van Moorselaar RJA, Craanen ME, Starink TM, Menko FH (2008) Birt-Hogg-Dubé syndrome: clinical and genetic studies of 20 families. J Invest Dermatol 128(1): 45-49

Lopez-Beltran A, Carrasco JC, Cheng L, Scarpelli M, Kirkali Z, Montironi R (2009) 2009 update on the classification of renal epithelial tumors in adults. Int J Urol 16(5): $432-443$

Menko FH, van Steensel MAM, Giraud S, Friis-Hansen L, Richard S, Ungari S, Nordenskjöld M, Hansen TV, Solly J, Maher ER (2009) Birt-Hogg-Dubé syndrome: diagnosis and management. Lancet Oncol 10(12): $1199-1206$

Nahorski M, Lim DHK, Martin L, Gille JP, Mckay K, Rehal PK, Ploeger HM, van Steensel M, Tomlinson IP, Latif F, Menko FH, Maher ER (2010) Investigation of the Birt-Hogg-Dubé tumour suppressor gene (FLCN) in familial and sporadic colorectal cancer. J Med Genet 47(6): 385-390

Nickerson ML, Warren MB, Toro JR, Matrosova V, Glenn G, Turner ML, Duray P, Merino M, Choyke P, Pavlovich CP, Sharma N, Walther M, Munroe D, Hill R, Maher E, Greenberg C, Lerman MI, Linehan WM, Zbar B, Schmidt LS (2002) Mutations in a novel gene lead to kidney tumors, lung wall defects, and benign tumors of the hair follicle in patients with the Birt-Hogg-Dubé syndrome. Cancer Cell 2(2): 157-164

Painter JN, Tapanainen H, Somer M, Tukiainen P, Aittomäki K (2005) A 4-bp deletion in the Birt-Hogg-Dubé gene (FLCN) causes dominantly inherited spontaneous pneumothorax. Am J Hum Genet 76(3): $522-527$

Pavlovich CP, Grubb III RL, Hurley K, Glenn GM, Toro J, Schmidt LS, Torres-Cabala C, Merino MJ, Zbar B, Choyke P, Walther MM, Linehan WM (2005) Evaluation and management of renal tumors in the BirtHogg-Dubé syndrome. J Urol 173(5): $1482-1486$

Pavlovich CP, Walther MA, Eyler RA, Hewitt SM, Zbar B, Linehan WM, Merino MJ (2002) Renal tumors in the Birt-Hogg-Dubé syndrome. Am J Surg Pathol 26(12): 1542 - 1552

Roth JS, Rabinowitz AD, Benson M, Grossman ME (1993) Bilateral renal cell carcinoma in the Birt-Hogg-Dubé syndrome. J Am Acad Dermatol 29(6): $1055-1056$
Schmidt LS, Nickerson ML, Warren MB, Glenn GM, Toro JR, Merino MJ, Turner ML, Choyke PL, Sharma N, Peterson J, Morrison P, Maher ER, Walther MM, Zbar B, Linehan WM (2005) Germline BHD-mutation spectrum and phenotype analysis of a large cohort of families with BirtHogg-Dubé syndrome. Am J Hum Genet 76(6): 1023 - 1033

Starink TM, Houweling AC, van Doorn MBA, Leter EM, Jaspars EH, van Moorselaar RJA, Postmus PE, Johannesma PC, van Waesberghe JH, Ploeger MH, Kramer MT, Gille JJP, Waisfisz Q, Menko FH (2011) Familial multiple discoid fibromas: a look-alike of Birt-Hogg-Dubé syndrome not linked to the FLCN locus. J Am Acad Dermatol; doi:10.1016/j.jaad.2010.11.039 (in press)

Starink TM, Kisch LS, Meijer CJLM (1985) Familial multiple trichodiscomas - a clinicopathologic study. Arch Dermatol 121(7): 888-891

Toro JR, Glenn G, Duray P, Darling T, Weirich G, Zbar B, Linehan M, Turner ML (1999) Birt-Hogg-Dubé syndrome - a novel marker of kidney neoplasia. Arch Dermatol 135(10): 1195- 1202

Toro JR, Pautler SE, Stewart L, Glenn GM, Weinreich M, Toure O, Wei MH, Schmidt LS, Davis L, Zbar B, Choyke P, Steinberg SM, Nguyen DM, Linehan WM (2007) Lung cysts, spontaneous pneumothorax, and genetic associations in 89 families with Birt-Hogg-Dubé syndrome. Am J Respir Crit Care Med 175(10): 1044-1053

Toro JR, Wei MH, Glenn GM, Weinreich M, Toure O, Vocke C, Turner M, Choyke P, Merino MJ, Pinto PA, Steinberg SM, Schmidt LS, Linehan WM (2008) BHD mutations, clinical and molecular genetic investigations of Birt-Hogg-Dubé syndrome: a new series of 50 families and a review of published reports. J Med Genet 45(6): $321-331$

Woodward ER, Ricketts C, Killick P, Gad S, Morris MR, Kavalier F, Hodgson SV, Giraud S, Bressac-de Paillerets B, Chapman C, Escudier B, Latif F, Richard S, Maher ER (2008) Familial non-VHL clear cell (conventional) renal cell carcinoma: clinical features, segregation analysis, and mutation analysis of FLCN. Clin Cancer Res 14(18): $5925-5930$

Zbar B, Alvord WG, Glenn G, Turner M, Pavlovich CP, Schmidt L, Walther M, Choyke P, Weirich G, Hewitt SM, Duray P, Gabril F, Greenberg C, Merino MJ, Toro J, Linehan WM (2002) Risk of renal and colonic neoplasms and spontaneous pneumothorax in the Birt-Hogg-Dubé syndrome. Cancer Epidemiol Biomarkers Prev 11(4): 393-400

This work is published under the standard license to publish agreement. After 12 months the work will become freely available and the license terms will switch to a Creative Commons Attribution-NonCommercial-Share Alike 3.0 Unported License. 